\title{
PPBE: Research on Operation and Latest Development
}

\author{
Lixiang Chen ${ }^{1,2}$ \\ ${ }^{1}$ Institute of Finance and Economics, Central University of Finance and Economics, Beijing, China \\ ${ }^{2}$ Department of Economics and Management, Taiyuan Institute of Technology, Taiyuan, China
}

\section{Email address: \\ clx906@163.com}

\section{To cite this article:}

Lixiang Chen. PPBE: Research on Operation and Latest Development. American Journal of Theoretical and Applied Business. Vol. 6, No. 4, 2020, pp. 98-105. doi: 10.11648/j.ajtab.20200604.17

Received: December 16, 2020; Accepted: December 24, 2020; Published: December 31, 2020

\begin{abstract}
PPBE (Planning-Planning-Budget-Execution System), is a multi-year, overlapping and rolling budget cycle process, which consists of four phases of planning, programming, budgeting, and execution. The purpose of PPBE is to establish a link between policy objectives and budgeting and form an effective defense resource allocation system with optimized combination of manpower, equipment, and support under certain resource constraints. Since the 1960s, PPBE has continued to make revisions and reforms with increasing changes of political, institutional environment. There were three important reforms, Laird reform, The Goldwater-Nichols Defense Restructuring Act, and Rumsfeld Reform. Since Rumsfeld's reform, the adjustment and development of PPBE is mainly to improve the efficiency of resource. Although budget management has its own emphasis in different periods, last development of PPBE is mainly flexibility, conciseness, and efficiency improvement. This paper reviews the evolution process and the latest development by historical analysis. After more than 60 years of evolution and development, PPBE continues to play an important strategic management function in the US Department of Defense. The study found that PPBE is more challenging for large organizations to maintain normal operation and improve adaptability and responsiveness in uncertain environments. In the 21 st century of conflict and uncertainty, it would be long-time challenge for PPBE to trade off increasing defense demand and decreasing financial constraints. Therefore, it is worthy of further studying how to improve the budget capability of PPBE participants in the future.
\end{abstract}

Keywords: Strategic Planning, Defense Resource Allocation, PPBE

\section{Introduction}

Planning Programming Budgeting Execution, PPBE, as the main tool for defense strategy planning and resources allocation in the United States, has a wide range of influence in the field of defense budgeting. The Predecessor of PPBE, PPBS, was first implemented in the US Department of Defense in the 1960s and later changed to PPBE, which is still in use today. It has not only shaped the modern US defense budgeting system, but also led the US public budgeting reform.

Most of the research on PPBE focused on the 1960s and 1970s, when the US federal government carried out the reform in an all-round way, and its evaluation was mixed. In the early stage, it is generally considered that PPBS practice failed to fulfill its promise [1, 2]. Since 1970s, scholars' research on PPBS has gradually decreased, but the applied research of PPBS in various public organizations has not disappeared, mainly focusing on the review and evaluation of PPBS in the US Department of Defense [3, 4]. In terms of reasons and characteristics of the transformation from PPBS to PPBE, Scholars thought that this transformation was a change in procedure or process rather than principle [5]. Scholars analyzed the management model and operational mechanism of PPBE after transformation by using the management cycle of "Planning, Execution, Checking and Action (PDCA)" [6]. This management paradigm provides a classic model for government management.

In the process of public budget reform, PPBE is a far-reaching budget innovation. With the disharmony between internal dynamics and external pressures in the public sector, this innovative practice of budgeting has had only limited success. The United States Department of Defense is a typical successful practice model of PPBE. This paper aims to lay the foundation and provide reference for the reform of government budgeting management by analyzing the experience, progress, challenges, and threats of 
the United States Department of Defense.

\section{PPBE and US National Defense Strategic Management}

PPBE is an important tool of national defense strategic management in the United States [7]. The essence of the National defense strategic management system is the process of strategic planning and resource management. Through this system, the American defense resource allocation realizes the two-way flow process from "threats and challenges -national security strategy and policy -- required military capability -- budgeting".

The three pillars of US defense strategy management system are Joint Capability Integration and Development System (JCIDS), Planning-Planning-Budget-Execution System (PPBE), and National Defense Acquisition System (DAS). JCIDS is mainly used to identify and confirm military capability requirements and capability gaps; PPBE provides optimized allocation and equipment, manpower, and resources for the activities of the Ministry of Defense; DAS forms specific equipment solutions based on the confirmed capability requirements, and realizes the effective transformation from defense funding to military capabilities. In the process of national defense resource allocation, demand, resources, and procurement are intersected and coordinated. The three systems are independent of each other and form a coordinated resource allocation system with capabilities as the core [8].

PPBE is the core of the US defense strategy management system, and has the dual functions of resource guarantee and strategic decision-making. PPBE is also an important mechanism for the U.S. Department of Defense to formulate military construction plans, determine specific plans, and prepare and execute budgets. PPBE organically integrates the military budget of the US military with the construction of weapons and equipment and military requirements, so that the realization of its national defense strategic goals is guaranteed by resources. In the management of U.S. defense strategy planning, programming review and budgeting review mainly assess whether services' programs reflect the capability requirements of the JCIDS system for confirmation and ranking, and whether the program objectives are reasonably priced; the affordability review through PPBE at the milestone decision points of the DAS system will determine whether to stop or replace the current plan or reallocate resources [9].

\section{Historical Evolution and Reform}

Before 1962, the Department of Defense did not have a coordinated planning and budgeting method. Each service proposes and protects its own budget, and the Secretary of Defense plays a limited role in budget review. After taking office as Secretary of Defense of the United States, McNamara tried to place the interests and preferences of various services and agencies of the Department of Defense under a broader concept of national interests, and through the involvement of senior civilian officials in defense planning management and budgeting, and weapon platform and system procurement plans. PPBS systematically analyzes military needs and integrates them into a five-year, plan-oriented defense budgeting system. Through this formal resource allocation system, the US Secretary of Defense has strengthened his centralization by using a top-down budgeting process. Of course, the process of integrating PPBS into the US Department of Defense has not been smooth sailing. Since then, the evolution and development of PPBS has undergone three major reforms.

\subsection{Laird Reform}

With the change of strategic environment and the advancement of military technology, the United States still couldn't end the Vietnam War because it invested a lot of defense funds and military power. At the same time, the Soviet Union's development and production capacity of nuclear weapons and large-scale traditional weapons threatened the position of the United States. These factors made the American people and Congress once very disappointed with the US Department of Defense. Melvin Laird, who took over as Secretary of Defense in 1969, was determined to end the Vietnam War and regain the trust of the US Congress and the people by this reform [10]. The important measures of its reform are as follows: First, the General Office of the Secretary of Defense no longer participates in detailed planning, but provides "budget ceiling" guidance to services and reviews programs and budgets submitted by services; Second, the Ministry of National Defense advocates "participatory management", and all services can participate in planning decisions, provided that the system analysis method advocated by McNamara continues to be adopted; Third, the system analysis office that had budget decision-making suggestions in the past was greatly degraded, and it was no longer authorized to propose national defense plans and development plans, but only required to analyze the plans proposed by services.

Some achievements have been made in this reform, and the "participatory management" method has greatly eased the contradiction between military and political affairs, which enabled the various services to cooperate to reduce the scale of defense budget and complete the withdrawal from Vietnam. However, the premise of "participatory management" is that all services have well-educated personnel who are capable of effectively evaluating plans and managing budgets. At that time, these conditions were not fully met by all services. Therefore, it is expected that controlling budget overruns through budget ceilings has not achieved ideal results.

\subsection{The Goldwater-Nichols Defense Restructuring Act}

From 1970s to 1980s, American military operations failed repeatedly, but defense spending continued to increase. The 
reformists in the United States began to reflect, thinking that the power competition among the Secretary of Defense, the Chairman of the Joint Chiefs of Staff, and the ministers of services has harmed the national security interests of the United States and brought about inefficient allocation of defense resources. After more than four years of intense debate and long-term game, the US Congress passed the Goldwater-Nichols Defense Restructuring Act in 1986. In terms of operational planning, the bill established the joint operational command system of the US military theater; In the allocation of resources, it is determined that the military needs should be managed hierarchically, and at the same time, the influence of the chairman of the Joint Chiefs of Staff in planning, programming and budget decision-making is enhanced. Military needs are clearly divided into joint operations needs and army building needs. The operational commanders in the war zones mainly put forward joint operation's needs, while the military services put forward army building needs. Finally, the military services are responsible for preparing plans and budgets according to military needs. The Chairman of the Joint Chiefs of Staff participated in the plan review and budget review and put forward suggestions to the Minister of National Defense on the plan suggestions and budget suggestions of various services and operational bureaus of the Ministry of National Defense, the degree of conformity of strategic planning, and the degree of conformity between the priority items determined by the military needs of theater commanders and the priority items determined in strategic planning. The bill clarifies the power boundary between theater commanders and various military departments in the joint operational command chain. However, in terms of resource allocation, theater commanders tend to pay attention to short-term operational needs, while various military services attach importance to long-term investment needs. This conflict between long-term and short-term military needs has brought challenges to the trade-off of national defense resource allocation.

\subsection{Rumsfeld Reform}

With the uncertainty of external threats after the end of the Cold War, the national defense strategic planning system originally established by the US military in the context of the Cold War is gradually unable to adapt to changes in the external environment. The "9.11" terrorist attack has brought a painful blow to the strategic planning system of the US military. The US military is more aware that the complex rigidity and complicated procedures of the defense budget system have restricted the formation of the US military's ability to respond quickly and flexibly, and it is necessary to simplify the budget procedures to improve operational efficiency. Therefore, from 2001 to 2003, the then Minister of National Defense Donald Rumsfeld led the reform of PPBS system, and the main contents of the reform: First, Rumsfeld's transformational reforms consolidate separate program and budget reviews into a single review cycle that is conducted simultaneously, rather than sequentially. Second, it incorporates budget procedures that match the national election cycle. In the absence of major changes in external security threats, major strategic changes will be made in the second year of the presidency, with minimal updates completed in the first and third years. Third, it fixes the time schedule of the process so that planning and budgeting is a derivative process driven by the quadrennial defense review and national military strategy. Fourth, it changed the period for the Office of the Secretary of Defense to provide top-level planning information to military departments and various services from an annual program to a multi-year program, and a joint program and budget review was conducted every two years. These changes formed a two-year program and budget review decision-making cycle (but not a biennial budgeting). The review was completed within one year, followed by a limited incremental review in the next year. The cycle change from sequentially separate program review and budget review to concurrently program and budget review aims to reduce the inefficiency of unnecessary replanning decisions.

Rumsfeld's reform has both positive and negative influences. The most successful part of its reform is to make the budget cycle better fit the US presidential administration and ensure the stability of the national defense strategic planning and resource allocation process during the US presidential administration. The budget changes in the biennium are also in line with the gradualism in the budget theory [11]. However, this kind of reform also aggravates the risk of planning and budget decision-making in even years, with double benefits for success and double disadvantages for failure. It can be said that if the US Congress maintains the annual budget allocation cycle, this strict biennial budget cycle seems impractical. In the later period of reform, PPBE reverted to the annual budget under the comprehensive action of various factors. The parallel mechanism of planning and budget was only implemented briefly in 2004 and 2005, and the budget activities returned to the traditional process in 2006 and beyond. From a practical point of view, the US Department of Defense pays attention to the budget implementation of PPBE. Although its reform direction is generally correct, at that time, the war between Iraq and Afghanistan involved more energy of the Ministry of Defense and occupied a lot of resources. At that time, the budget implementation was not really institutionalized, so the results were not significant.

\section{Operation and Latest Development of PPBE}

PPBE is a process of strategic implementation. The original intention of designing this system is to make it a bridge between strategic planning and resource allocation. Although PPBE and its predecessor PPBS have undergone several changes, the basic elements and system analysis methods of the budget system designed by McNamara at that time have been inherited. After decades of development and 
evolution, the basic structure and operation of PPBE are becoming more and more perfect.

\subsection{PPBE Operation Process}

According to the budget process, the operation process of PPBE is carried out by four stages in turn, namely, planning, programming, budgeting, and execution stages (see Figure 1). First, the planning stage. At this stage, under the guidance of National Security Strategy, National Defense Strategy and National Military Strategy of the United States, the future medium and long-term defense strategy conception and plan arrangement are formulated. According to the national security and military strategy, the Joint Chiefs of Staff transforms strategic needs into military capability needs and guides the focus and direction of army building. Office of the Secretary of Defense (OSD) is the leading organization in the planning stage, and the most important achievement in this stage is the Defense Planning Guide (DPG), which provides guidance for the adjustment and planning of the force structure of various US military services in the future. Second, the programming stage. At this stage, according to the Defense Planning Guide, each service and each agency of the Department of Defense prepared the Program Objectives Memorandum (POM) and then submitted it to OSD for review. This is a medium-term program covering five fiscal years, describing the future program priorities, task priorities and the ability to use resources. The Chairman's Program Assessment (CPA) signed by the Chairman of the Joint
Chiefs of Staff (CJCS) during the programming process is an important document affecting program review, and its main contents include the military evaluation opinions of services and the Joint Staff. Third, the budgeting stage. Each service and the agency of DOD estimate the cost of the approved program, prepare the Budget Estimate Submission (BES), and submit it to the Office of the Secretary of Defense for budget review. The essence of this budgeting process is to estimate the program for the first year (budget year) in POM for submission to Congress for authorization and appropriation and implementation. During the budget review process, if services and defense agency have opinions or appeals on the budget review decision, they will respond and negotiate by submitting Major Budget Issues (MBI). The decision after passing the program and budget review shall be recorded in the "Resource Management Decision" (RMD) to form a national defense budget plan to be officially reported. The Office of the Secretary of Defense submits the final budget to the Office of Management and Budget (OMB) for review and submits it to Congress as part of the US President's budget. Fourth, execution phase. The execution stage is relatively independent in the entire budget process. After the presidential budget is reviewed by Congress and the budget authorization bill and appropriation bill are promulgated, the defense budget enters the execution, completing four phases operation of "planning-planning-budgeting-execution".

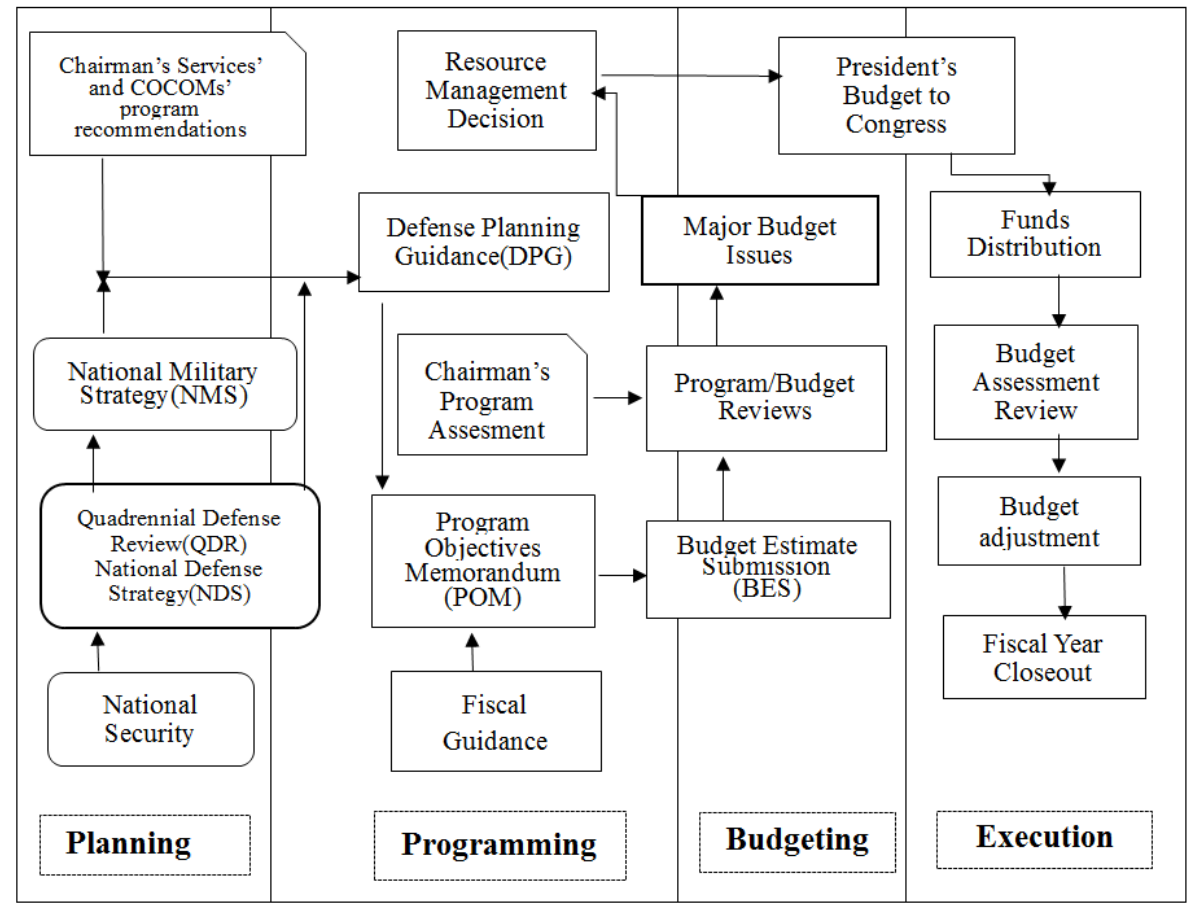

Source: https://acqnotes.com/acqnote/acquisitions/ppbe-overview

Figure 1. PPBE Process Overview.

PPBE process is a time-driven and dynamic cycle process. First, PPBE is time-driven. The U.S. Constitution requires the president to submit his budget to Congress no later than the first Monday in February. As an important part of the government budget, the defense budget must run in line with the government budget cycle. Among the four phases of 
PPBE, the planning and budgeting stages are the most time-driven. In the planning phase, the strategic guidance is issued for a long time (5 10 years or even longer), while the programming is medium-term ( 5 years), the budgeting is annual, and the program and budget review is carried out according to the time schedule stipulated every year. The Office of the Secretary of Defense will issue documents every year, which will stipulate the key nodes of each process and the deadline for submission.

Secondly, from the perspective of resource allocation dynamic operation, PPBE has the characteristics of overlapping, inter-annual, and rolling budget cycles (see figure 2). The fiscal year in the United States is inconsistent with the calendar year. The fiscal year is from October 1 st of the calendar year to September 30th of the next year. The
Ministry of National Defense must complete three budget activities in a fiscal year, the first is to implement the budget of this fiscal year, and the second is to review the budget of the budget year (this fiscal year +1 ) three months before the start of the fiscal year, including plan review and budget review, and then submit it to the federal government to form the next year's presidential budget. The third item is the planning for the planning year (this fiscal year +2 ). Each fiscal year is an overlapping cross-year budget process for each stage of PPBE. Normally, it takes at least 18 months for a new plan to enter the planning stage until the presidential budget is presented to Congress, and it takes at least 8 months for Congress to authorize and allocate funds. Therefore, it takes at least 26 months for a new plan to obtain funds according to the normal process [12].

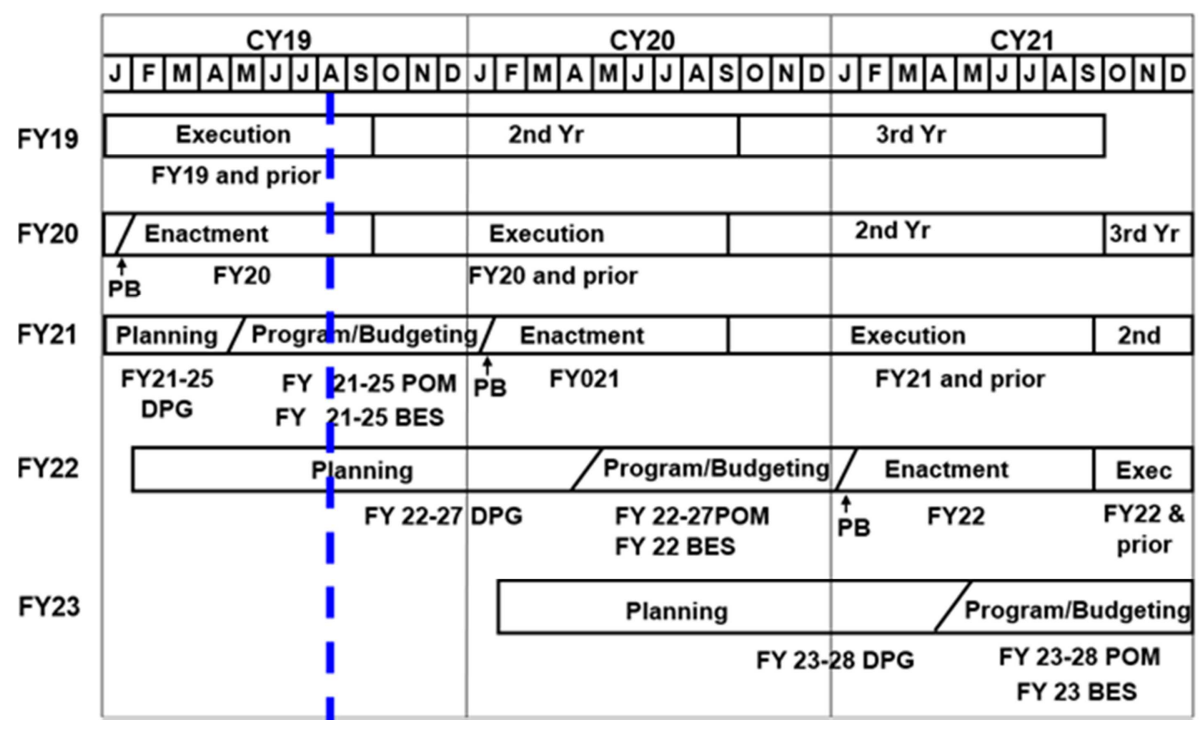

Figure 2. Resource allocation process.

\subsection{The Latest Development of PPBE}

Since Rumsfeld's reform, the adjustment and development of PPBE is mainly to improve the efficiency of resource. Although budget management has its own emphasis in different periods, the theme of PPBE development is flexibility, conciseness, and efficiency improvement. The reform of Secretary of Defense Gates emphasized "capability portfolio management" to influence the planning and planning stage of PPBE. During President Obama's period (2011-2017), PPBE was mainly manifested in the return of budget process to history. During Trump's administration, PPBE emphasized improving budget performance management. The latest development of PPBE is mainly manifested in the following three aspects.

The first is to emphasize the capability portfolio management. During Rumsfeld's period, the Department of Defense put forward tools, methods and procedures based on capability planning, but it did not become a formal institutionalized process. In 2010, Gates, then Secretary of Defense, made great reforms in the institutionalization of capacity planning methods. The Front-end review (FEA) is proposed in the planning stage of PPBE, and the capability portfolio management (CPM) is introduced in the planning stage. The content of the front-end review is to assess the applicability of military capabilities and planning strategies, and major issues identified by the Department of Defense. This review takes place in the strategic combination process in the planning stage and before each service and Defense agency begins to prepare their POM, and its review results will be used to guide the preparation of the Program Objective Memorandum. Front-end review was used for the first time in the planning and budgeting process of fiscal year 2012-2016, and then changed to strategic portfolio assessment report (SPR) [13]. Capability portfolio management attempts to divide all current and future planned operational requirements into different functional categories that can be managed hierarchically, and provides cross-departmental selection, current and future capability requirements, and investment suggestions, which are submitted to the Deputy Secretary of Defense Proposal Working Group (DAWG). However, the suggestions of competency portfolio management can only be searched at the end of PPBE programming stage, which fails to show great influence. In addition, with the transformation of 
strategic planning, various programming guidelines have also changed. On April 9, 2010, Secretary of Defense Gates integrated various guidelines and guidance documents in the planning stage, and the Strategic Planning Guide (SPG) and Joint Programming Guide (JPG) were integrated into National Defense Planning and Programming Guidance (DPPG) [13]. During the Panetta period in 2011, the new planning document "Defense Planning Guidance" (DPG) replaced this "Defense Planning and Programming Guide".

Second, PPBE process reengineering. PPBE's program and budget review has gradually returned from parallel to the past sequence. Rumsfeld's biennial budget and parallel program and budget review were only implemented in 2004 and 2005, and returned to the traditional budget process in 2006. The National Defense Budget Authorization Act (Part 1006) in fiscal year 2008 officially abolished the biennial budget, and the concepts of "on-year" or "off-year" were no longer used [14]. This is explained in the important guidance document of PPBE, Department of Defense Directive No. 7045.14 (January 25, 2013). The budget covers only one year, and program and budget should be prepared every year. Later, senior defense officials of US Deputy Secretary of Defense, Robert Walker said that the Pentagon had started a major effort to "Reset" PPBE. Walker pointed out in the memorandum on December 11, 2014 that "since the fiscal year 2017, the PPBE budget process has returned to historical sequence process in turn. I believe that doing so will provide more opportunities for the defense department's program and budget to be consistent with strategic guidance." [15] This was officially confirmed in the National Defense Budget Authorization Act of 2015 and has been implemented since the 2017 fiscal year.

Third, strengthen budget performance management. The Execution stage of PPBE has been criticized since 2003, which is regarded as "silent implementation", and even thinks that the Department of Defense has not systematically managed the implementation of its funds. With the adoption of the Government Performance and Results Modernization Act (GPRAMA, 2010), the law requires federal departments and agencies to strengthen performance management. The U.S. Department of Defense has established a Chief Management Officer (CMO) in accordance with the requirements of the National Defense Authorization Action Act of 2017, and has continuously strengthened its powers and responsibilities, ranking only behind the Secretary of Defense and the Deputy Secretary. Its focus is to collect and analyze the cost data of each department and evaluate the performance, and to improve the management performance through the close combination of cost and performance information [16]. In order to further strengthen the responsibility and supervision of defense budget, in December 2018, the US Department of Defense started the first audit of comprehensive business financial statements of DOD-wide. The audit also revealed long-standing problems in defense budget management. The US Department of Defense has begun to improve the discipline and consistency of operations, so that it can reallocate resources to the most important priorities according to the national defense strategy [17].

\section{Challenges and Trends of PPBE Development}

After more than 60 years of evolution and development, PPBE continues to play an important strategic management function in the US Department of Defense. Nevertheless, the future development of PPBE still faces many challenges.

First, the challenge of complex national defense strategic environment. The U.S. military believes that its strategic environment is further complicated by nuclear proliferation, violent extremism and a series of constant military action challenges, and its military innovation is also challenged by its potential competitors and threatens the projection power of the United States. Facing the complicated external environment and diversified military needs, the traditional strategic planning model of PPBE is obviously rigid and lagging. Since PPBE was established under the security environment of single threat during the Cold War, its strategic planning process will pursue over-standardization of planning scenarios, models and data and over-evaluation of organizations. Therefore, under the situation of diversified threats, PPBE planning is more like "wish list of military needs", which does not form competitive planning, and the defense planning guide cannot guide the business organizations of various military departments and the Ministry of National Defense in a timely and effective manner.

Second, the uncertainty challenge of defense budget. This uncertainty mainly involves two aspects: sustainability of budget growth and budget implementation. On one hand, the pressure of defense budget growth comes from debt interest payment, domestic priorities, and the uncertain balance of power in the future Congress may undermine budget sustainability. On the other hand, there is uncertainty in budget implementation. According to the 2017 report of the Center for New Security Studies (CNAS), the defense budget has suffered one budget crisis after another in recent ten years. The defense budget is not only maintained by a series of continuous agreements (CR) and short-term budget agreements, but also faces the double threats of automatic expenditure reduction and government closure. [18] The U.S. Congress has not passed the final defense appropriation bill on time since 2009, and Congress has passed about 30 persistent resolutions, of which the Department of Defense operates according to persistent resolutions for about one third of the time, with the longest duration exceeding 7 months. As the name implies, during the continuous period, the budget can only maintain the expenditure level of the previous year, and it is impossible to transfer expenditures between different accounts or add new projects, which undoubtedly increases the extra difficulties in budget implementation.

Third, the mismatch between national defense strategy and 
national defense budget. With the increasing gap between the expenditure needed by the United States to maintain its hegemonic dominant strategy and its economic strength, the mismatch between national defense strategy and national defense budget is worsening. As an important tool of national defense strategic management, PPBE is mainly used to prepare national defense budget based on strategic orientation. The persistent mismatch between national defense strategy and national defense budget not only directly affects the operation effect of PPBE system, but also may lay the foundation for national defense reduction when the budget pressure increases in the future. Although US President Trump's defense budget expenditure has been increasing during his administration, it seems that the defense budget can support the defense strategy from the perspective of budget investment, but the disconnection between budget investment and strategic priority has been controversial. The U.S. military also acknowledges that there is an obvious mismatch between the defense budget application in FY 2019 and the defense strategy, and hopes that the budget in FY 2020 will be more in line with the strategy. [19] The analysis of the 2019 report of the Center for Strategic and Budgetary Evaluation (CSBA) shows that the US defense budget application in FY 2020 still fails to fully support the US defense strategy in 2018, and it is expected that the gap between the future defense strategy and budget will still exist [20].

Fourth, the limitations of PPBE itself. The design of PPBE assumes of the separation of politics and administration, which pays attention to the optimization process of internal interests and ignores external political interests. The basic resource allocation unit of PPBE is program, not organization. There are some conflicts between this cross-organizational resource reorganization process and bureaucratic administrative management process. The coordination of the conflict between the two becomes more complicated under the pluralistic politics and decentralization system in the United States. Looking back at history, in the mid-1960s, PPBS rose from reform to failure in the US federal government, and then in the 21 st century, PPBE in the US non-defense sector went from revival to gloom, which also shows to a certain extent that the conflict and coordination process brought by PPBE always affected its reform process [21].

Although faced with many challenges such as changing security environment, resources and uncertainty, the development of PPBE is facing great controversy, it can also be seen from the current development of some basic trends in the future of PPBE. First, the PPBE budget process will be further streamlined. In view of the slow and complex PPBE process, there has been a long-standing controversy in the academic and practical circles in the United States over its budget process reform. One of the major controversies is that the fragmentation of PPBE's program and the lengthy review process lead to the failure of the program to guide the budget preparation in time, the destruction of the normal budget process and procedures, and the serious impact on budget performance [22]. Therefore, some scholars have continuously proposed that the PPBE process should be simplified into a two-stage planning-budgeting system, or replaced by a longer-term budgeting, or even proposed to cancel Program Objectives Memorandum [23]. It is difficult to be sure whether it can meet the expectations of scholars, but from the present point of view, PPBE should continue to simplify the budget process in the future to respond to the criticism of the national defense system and academia.

Second, the budget execution and accountability system of PPBE will be continuously strengthened. Strengthening the budget execution and accountability of PPBE is an important aspect to realize the integration of budget and performance management. However, in the past, the US Department of Defense has been controversial, and the first comprehensive audit of defense business activities that ended at the end of 2018 exposed the long-standing problems in the US defense budget. Then, in August 2019, the U.S. Department of Defense launched a comprehensive zero-based review of all functions and activities of the whole department, aiming at reducing expenditure to support the management reform goal of the Department of Defense [24]. Therefore, the US Department of Defense will continue to strengthen PPBE implementation and accountability and pursue budget performance management.

Third, the effective connection between PPBE and other two strategic planning systems (DAS and JCIDS) will be further strengthened. As the three pillars of American defense strategic planning system, PPBE, DAS and JCIDS are both independent and overlapping, providing decision support for the implementation of strategic objectives. However, there are still some frictions among the three systems in actual operation, and the U.S. Department of Defense has not done less work on the organization coordination and joint review of the three systems. However, these efforts have not made the interaction mechanism between the three systems really connect effectively and play a role. At present, there are still many obstacles, such as the low design quality of information sharing and interaction mechanism among the systems, the high cost of supervision and control of the design and development of the new management information system, the repeated accounting and analysis of project costs by different participants and the overestimation of planned budget, which still plague the effective connection between the systems. Therefore, in the future, the US Department of Defense should make continuous efforts to effectively link up the national defense strategic planning system.

\section{Conclusion}

Since the 1960s, PPBE has continued to make revisions and reforms in Department of Defense in American. It has always solved the problem of the connection between long-term defense planning and short-term budgeting, and formed an effective defense resource allocation system with optimized combination of manpower, equipment, and support under certain resource constraints. In the 21 st century of 
conflict and uncertainty, it would be long-time challenge for PPBE to trade off increasing defense demand and decreasing financial constraints. Therefore, it is worthy of further studying how to improve the budget capability of PPBE participants in the future.

\section{References}

[1] Schick, A. (1973). A death in the bureaucracy: the demise of federal PPB. Public Administration Review, 146-156.

[2] Church, A. T. \& Warner, T. (2009). DoD Planning Programming Budgeting and Execution System: A Path Toward Improvement. JFQ: Joint Force Quarterly (53), 80-84.

[3] Chwastiak, M. (2001). Taming the untamable: planning, programming and budgeting and the normalization of war. Accounting, Organizations and Society, 26 (6), 501-519. doi: https://doi.org/10.1016/S0361-3682(01)00010-1.

[4] Team, J. D. C. S. (2004). Joint Defense Capabilities Study: Improving DoD Strategic Planning, Resourcing, and Execution to Satisfy Joint Capabilities: US Department of Defense.

[5] Grimes, S. R. (2008). PPBS To PPBE: A Process Or Principles? ARMY WAR COLL CARLISLE BARRACKS PA.

[6] Melese, F., Appleby, C. \& Larsen, B. (2006). A review and update of public budgeting in defense: Leveraging a new management model for government. DRMI Working Papers Ongoing Research.

[7] Jones, L. R., Candreva, P. J. \& DeVore, M. R. (2014). Financing National Defense: Policy and Process. Charlotte, NC: Information Age Publishing, Incorporated.

[8] Fast, W. R. U. (2010). IMPROVING DEFENSE ACQUISITION DECISION MAKING. Defense AR Journal, 17 (2), 220-241.

[9] Jones, L. R. \& McCaffery, J. L. (2005). Defense acquisition and budgeting: Investigating the adequacy of linkage between systems. International Public Management Review, 6 (2), 87-115.

[10] Benson, L. R. (2015). Melvin Laird and the Foundation of the Post-Vietnam Military, 1969-1973. Air Power History, 62 (4), 58-59.

[11] Jones, L. R. \& McCaffery, J. L. (2005). Reform of the Planning, Programming, Budgeting System, and Management Control in the U.S. Department of Defense: Insights from Budget Theory. Public Budgeting \& Finance, 25 (3), 1-19.
[12] Potvin, L. (2013). Practical Financial Management: a handbook for the Defense Department Financial Manager//2013.

[13] College, U. S. A. W. (2015). Army Organization in How the Army Runs: A Senior Leader Reference Handbook (2013-2014).

[14] Congress, U. S. (2007). National defense authorization act for fiscal year 2008: $\mathrm{S}$.

[15] Bertuca, T. (2014). DOD Begins Major Planning, Programming, Budgeting And Execution'Reset'. Inside the Navy, 27 (50), 11.

[16] Hale, R. (2016). A Role For DoD's New Under Secretary. Available at: https://www.defensenews.com/opinion/commentary/2016/08/ 03/a-role-for-dod-s-new-under-secretary/. Accessed 10-03, 2019.

[17] Raj Gnanarajah. (2019). Defense Primer: FY2018 Department of Defense Audit Results. Available at: https://crsreports.congress.gov/product/details?prodcode=IF10 913. Accessed.

[18] Blume, S. V. \& Lauren, F. (2017). A Brief History of Defense Budget Instability: Center for a New American Security.

[19] Andrew, H. (2019). Budget Strategy Mismatch. Armada International, 43 (6), 34.

[20] Sharp, T. (2019). DID DOLLARS FOLLOW STRATEGY? ANALYSIS OF THE 2020 DEFENSE BUDGET REQUEST. Available at: https://csbaonline.org/research/publications/did-dollars-follow -strategy-a-review-of-the-fy-2020-defense-budget. Accessed.

[21] West, W. F., Lindquist, E. \& Mosher-Howe, K. N. (2009). NOAA's Resurrection of Program Budgeting: Déjà Vu All Over Again? Public Administration Review, 69 (3), 435-447, 370. doi: 10.1111/j.1540-6210.2009.01990.x.

[22] Gansler, J. S. \& Lucyshyn, W. (2015). Reforming acquisition: This time must be different: MARYLAND UNIV COLLEGE PARK CENTER FOR PUBLIC POLICY AND PRIVATE ENTERPRISE.

[23] McCaffery, J. \& Jones, L. (2007). Budgeting and Acquisition Business Process Reform.

[24] Daniels, S. P. (2019). Understanding DoD's Defense-Wide Zero-Based Review. Available at: https://defense360.csis.org/understanding-dods-defense-widezero-based-review/. Accessed 12-10, 2020. 